\title{
Do acoustic cues mediate host finding by Syngaster lepidus (Hymenoptera: Braconidae)?
}

\author{
A. L. Joyce · J. G. Millar • J. S. Gill • M. Singh • \\ D. Tanner $\cdot$ T. D. Paine
}

Received: 7 June 2010/Accepted: 4 October 2010/Published online: 21 October 2010

(C) The Author(s) 2010. This article is published with open access at Springerlink.com

\begin{abstract}
Syngaster lepidus Brulle is a braconid solitary ectoparasitoid that attacks the larvae of the cerambycid beetles Phoracantha semipunctata and Phoracantha recurva. The beetle larvae are concealed under the bark of their Eucalyptus host trees feeding at the interface of the inner bark and the wood. Ovipositing female parasitoids search the bark surface and must first locate a host larva accurately, drill through as much as $1 \mathrm{~cm}$ of the bark in order to paralyze the larva beneath, and lay a single egg on the paralyzed larva. Female wasps were provided with logs infested with host larvae, in which the positions of the host larvae had been determined by X-ray imaging. The sequence of behaviors following the landing of a female wasp on an
\end{abstract}

Handling Editor: Torsten Meiners.

A. L. Joyce - J. G. Millar · J. S. Gill · M. Singh ·

D. Tanner · T. D. Paine $(\bowtie)$

Department of Entomology, University of California,

Riverside, CA 92521, USA

e-mail: timothy.paine@ucr.edu

Present Address:

A. L. Joyce

Sierra Nevada Institute, University of California,

Merced, CA, USA

Present Address:

D. Tanner

Department of Biology, Utah State University,

Logan, UT, USA infested log was recorded on videotape and subsequently analyzed to provide a detailed description of the processes of host location and oviposition. Female wasps searched significantly more on log sections with active host larvae than inactive larvae. They also turned toward and moved in the direction of active larvae in response to sounds produced by feeding. While searching for hosts, female wasps stand on the $\log$ surface and walk towards the location of the larvae; while it is possible that they perceive both airborne sound and associated surface vibration, the vibration signals are probably more important in indicating direction and possibly distance to the host.

\section{Keywords Syngaster lepidus - Phoracantha} semipunctata P Phoracantha recurva . Host location . Substrate-borne vibration - Vibrotaxis .

Airborne sound

\section{Introduction}

Parasitoid wasps must find suitable hosts in order to reproduce. Host finding consists of a sequence of overlapping steps, including location of habitats likely to contain hosts, location of hosts within that habitat, host recognition, and host acceptance and suitability (Vinson 1976). To date, most research on host finding by parasitoids has focused on wasps that attack exposed hosts, with less emphasis being placed 
on wasps that parasitize concealed hosts in stems, woody tissues, or other solid substrates. Furthermore, the comparatively few studies that document the use of acoustic cues by parasitic wasps for host location have focused on short-range vibrational cues for host finding and host acceptance (Meyhofer et al. 1997; Meyhofer and Casas 1999; Djemai et al. 2004) rather than host location from longer distances.

The Australian parasitoid wasp, Syngaster lepidus Brullé (Hymenoptera: Braconidae) (Austin et al. 1994), was imported into California, USA as a biological control agent for two introduced beetle species, Phoracantha semipunctata F. and Phoracantha recurva Newman (Coleoptera: Cerambycidae). Phoracantha semipunctata was first detected infesting Eucalyptus trees in southern California around 1984 (Scriven et al. 1986), and $P$. recurva was first identified from the same part of the state in 1995 (Hanks et al. 1997). The adult beetles are attracted to stressed or fallen trees, where mating and oviposition occur (Hanks et al. 1993; Paine and Millar 2002). The beetle larvae develop in a concealed environment under the bark, feeding on cambium and bark tissues, and rapidly kill their hosts (Froggatt 1916). Feeding Phoracantha larvae produce audible sounds and vibrations due to the rasping of their mandibles on the substrate as they feed (Paine et al. 2001), and these acoustic signals could be exploited by searching wasps and used for host location or acceptance. Understanding whether parasitoids detect host produced sounds and vibrations, as well as how they transmit through natural and artificial rearing substrates, could improve mass rearing of these wasps for augmentative biological control programs (Joyce et al. 2008; Joyce et al. 2010).

Syngaster lepidus is a solitary ectoparasitoid, which uses its ovipositor to probe through the tree bark into the tunnel in the cambium containing host larvae (Moore 1963; Paine et al. 2000; Millar et al. 2002; Joyce et al. 2002). The wasp injects a paralyzing venom into the host larva, and an egg is oviposited on the cuticle of the immobilized host. The parasitoid larva feeds by consuming host fluids and tissue, and eventually forms a papery cocoon for pupation within the host larval gallery (ALJ, Pers. Obs.).

It seems likely that female $S$. lepidus use visual or olfactory stimuli as long-range cues to locate suitable environments containing hosts (i.e., infested
Eucalyptus trees or logs). Once on an infested log, female wasps could use host-produced sounds/vibrations rather than visual or olfactory cues to locate the Phoracantha larvae concealed below the bark within the log. Since S. lepidus are ovipositing into beetle larvae that are concealed under $\sim 1 \mathrm{~cm}$ of Eucalyptus bark, it is unlikely that visual cues are used to evaluate location or quality of the larval host. For example, field observations of S. lepidus indicated that searching wasps adopted a characteristic behavioral sequence in which short bursts of walking were interspersed with wasps adopting a motionless "listening" pose, followed by further oriented movement towards a host larva (Hanks et al. 2001).

There is some evidence that various parasitoids make use of acoustic cues to locate hosts, either alone or in combination with chemical cues. For example, vibrotaxis is used by parasitoids of Drosophilidae (Sokolowski and Turlings 1987). Sugimoto et al. (1988) demonstrated that Dapsilarthra rufiventvis (Hymenoptera: Braconidae) responded to acoustic cues associated with its leafminer hosts. Host finding using vibration in the absence of chemical cues has only recently been demonstrated (Djemai et al. 2004). However, there is also evidence from other systems that acoustic cues may not be required to locate hosts hidden in solid substrates. For example, Richerson and Borden (1971) stated that host-produced vibrations were not obligatory in host location and acceptance by the bark beetle parasitoid Coeloides vancouverensis (D.T.) exploiting cryptic Dendroctonus pseudotsugae Hopkins hosts, suggesting instead that infrared signals might be involved. In contrast, a later study by Mills et al. (1991) in a similar system consisting of the braconid parasitoids Coeloides bostrychorum Gir. and Dendrosoter middendorffi (Ratz.) parasitizing larvae of the bark beetle Ips typographus L. found no evidence for the involvement of either acoustic or infrared cues. Instead, the evidence suggested that volatile odors associated with hosts were the primary cue used by the parasitoids for host location.

Thus, it seems most likely that S. lepidus could exploit chemical or acoustic cues to locate its Phoracantha hosts. The involvement of visual cues can probably be ruled out by the fact that the host larvae are hidden under the bark, usually many centimeters away from the original oviposition site. It also does not seem likely that infrared cues 
associated with hosts could be exploited because $S$. lepidus are diurnally active, and light and shadow across the bark surface could create a patchwork of different temperatures. Here, we describe the results of experiments to determine the possible role of acoustic signals in host finding by S. lepidus, and specifically, if there was a relationship between host finding and the sound and vibration produced by host larvae as they feed. The scraping sounds produced by Phoracantha larvae as they feed are remarkably loud, being easily discernable to the human ear from a distance of several meters away. Thus, our objectives were as follows:

1. To describe the short range host finding behavior of adult female $S$. lepidus parasitoids,

2. To correlate the presence or absence of host feeding sounds/vibrations with movement by the parasitoid, and

3. To determine if wasps located hosts via direct attraction (taxis) to acoustic cues from the host, or indirect attraction through increased turning frequency (kinesis) as searching females approached the host larvae.

\section{Materials and methods}

Insect colonies and host plants

Log sections of Eucalyptus camaldulensis $(\sim 10 \mathrm{~cm}$ diameter $\times 40 \mathrm{~cm}$ long) were cut from trees felled from a plantation at Rancho Santa Margarita Field Station near Temecula, California, USA. Logs were stood vertically on absorbent paper in the laboratory at $27 \pm 2{ }^{\circ} \mathrm{C}$ and $50 \%$ relative humidity ( $\mathrm{RH}$ ) to permit excess water to drain from the wood. After drying for ten days, the cut ends of the logs were dipped in melted Parowax paraffin wax, to seal the $\log$ and maintain residual log moisture.

Phoracantha recurva adults were obtained from a colony maintained continuously in the laboratory since 1996, using methods developed for the congeneric species P. semipunctata (Hanks et al. 1993). Groups of adults (five female and three male) were placed in screen wire cages lined at the bottom with layers of waxed paper as an oviposition substrate. Eucalyptus pollen and sugar water were provided as food for the adults. The cages were checked daily and egg masses were removed. The eggs were held at $27 \pm 2{ }^{\circ} \mathrm{C}$ and $50 \%$ relative humidity (RH) until neonate larvae enclosed.

Logs were infested with newly enclosed $P$. recurva larvae ( $<48 \mathrm{~h}$ since hatch) the day following waxing. A utility knife was used to make an incision in the side of each log approximately $5 \mathrm{~cm}$ long $\times 0.5 \mathrm{~cm}$ deep into which a single neonate larvae was transferred with a fine paintbrush. A single larva was used in each log so that the behavior of a female parasitoid could be recorded with respect to the distance from the host larvae. Logs were incubated in a greenhouse at $25^{\circ} \mathrm{C} \pm 5^{\circ} \mathrm{C}$ and $50 \% \mathrm{RH}$ for approximately four weeks. Each log was then taken to the student health center on the UC Riverside campus and photographed using an X-ray machine. Metal reference pins were inserted into the bark prior to imaging so that the precise point on the bark above the larva could be determined using comparisons of the pins on the log and the position of the larva on the image.

Adult S. lepidus were obtained from an established laboratory colony maintained on both $P$. recurva and $P$. semipunctata larvae in Eucalyptus logs as described in Millar et al. (2002). Each group of logs used to produce beetles or parasitoid adults was maintained in the greenhouse $\sim$ six weeks and then discarded. After emergence, adult wasps were placed in large screen cages $(1 \mathrm{~m}$ on each side) with logs containing host larvae at suitable developmental stages to allow both mating and oviposition. After 7-10 days, the logs were then transferred to a greenhouse at $27 \pm 2^{\circ} \mathrm{C}$ for parasitoid development, and then placed in sealed cardboard boxes $(60 \mathrm{~cm} \times 60 \mathrm{~cm} \times 45 \mathrm{~cm})$ with a one liter clear glass jar attached to one side to collect the positively phototactic adults as they emerged. Adult wasps were collected from the jars twice daily. Newly emerged female wasps used for observations of searching behavior were standardized in age and experience by collecting them from the lab colony within $24 \mathrm{~h}$ of emergence. After mating, females were given oviposition experience by exposing them to logs infested with larval hosts for $48 \mathrm{~h}$. Females were then isolated with only honey and water for 5-7 days before being used in a trial.

Host searching behavior of female S. lepidus

Searching behavior of individual adult female S. lepidus on a Eucalyptus log infested with one 
$P$. recurva larva was filmed on VHS video tape with a Sony DXC-537 video camera while simultaneously recording the sounds of the host larva feeding with both a condenser microphone (AKG C-1000) and an electronic stethoscope (Omega HHT91) onto the right and left audio channels on the video tape. Each experimental $\log$ was placed into a plexiglass cage $(15 \times 15 \times 30 \mathrm{~cm})$, with one side fitted with screen so that sounds from a feeding larva could be heard outside the cage. The log was positioned so that the larva was on the top surface of the log, and the wasp behavior could be observed and recorded in relation to the location of the feeding larva. Prior to recording, the condenser microphone was positioned outside of the cage approximately $10 \mathrm{~cm}$ from the log to record airborne sound and the electronic stethoscope was placed on the $\log \sim 2-4 \mathrm{~cm}$ from the feeding larva, to record sound and vibrations. Both audio sources were amplified through a Mackey 1402 VLZ mixer and an outboard time code generator and finally recorded onto the video tape, so that sound and behavior were synchronized. Filming began when a wasp landed on the $\log$ and continued until probing occurred, or until the wasp abandoned the log. Behaviors were reviewed on a monitor during filming, and headphones were used to monitor and listen to larval feeding sounds during the video recording. Seventeen video tracks each approximately $20 \mathrm{~min}$ in duration of females searching for hosts that resulted in probing behavior were obtained for analyses.

\section{Choice experiment: active or immobilized larvae}

In a second experiment, a searching female was exposed to logs containing a normal host larva and a host larva that had been stung and parasitized by a female wasp. Once parasitized, the host larva remained alive but could not emit sounds or vibrations by movement. In contrast, the larva in the other half of the $\log$ had not been exposed to parasitization and remained mobile and capable of producing sounds and vibrations through movement and feeding.

To prepare a log for the choice experiment, a larva was introduced into each end of a log as previously described. X-ray images were used to map the positions of the larvae. One of the two larvae were then protected from parasitization by placing a cardboard and foil tube or skirt over that portion of the $\log$. The skirted $\log$ was placed within a cage containing approximately 100-200 female S. lepidus adult wasps for 4-5 days to permit parasitization of the unprotected larva. This cage was constructed in a similar fashion to the cage used for rearing S. lepidus. The treatment $\log$ and approximately 20 additional infested but unprotected $\operatorname{logs}$ were placed vertically spaced approximately $3-5 \mathrm{~cm}$ apart. The length of the oviposition interval (4-5 days) and the number of searching females insured that any exposed and active larva was parasitized.

After the first oviposition interval, the log containing one parasitized and one unparasitized larva then was removed from the cage and the protective skirting was removed to expose the bark surface concealing both larvae. The log was placed into a second oviposition cage containing 100-150 adult female wasps the next day. As in the first oviposition cage, the second cage also contained other infested logs. A digital video camera (Sony Network Handycam DCR-TRV50) was stationed on a tripod directly outside a plexiglass window in the cage. The video recorded the movements of wasps landing on the log. A parabolic microphone (National Geographic Listening Dish) was attached to the camera and positioned to capture sounds emitted only by the unparasitized larva in the experimental log, which were many times louder than larvae in the surrounding logs. These two instruments simultaneously captured sounds emitted by the larva and the patterns of wasp searching behaviors. A total of 43 wasp searching sequences (landing on the surface to departure) were recorded from 36 logs. The tapes were analyzed for the sequence of behaviors and the relationship between larval sounds and wasp movements.

\section{Data analysis}

The video recordings for 17 searching females in the first experiment were reviewed and parasitoid behavior was recorded for each second from the video tracks that led to probing through the bark. Behaviors were categorized to build an ethogram. The frequencies and mean durations of behavioral events were determined using Proc means and Proc freq in SAS (1996). The audio was recorded from females 11-17, for a total of seven tracks with females that included host larval feeding sounds. For each second of video, the presence or absence of sound was noted. 
The mean duration of resting (seconds) prior to turning or walking was compared on all 17 tracks using a one-way analysis of variance. On the seven tracks that had sound, a similar analysis was conducted. We used $\chi^{2}$ analysis to compare the frequency of resting females transitioning to either walking, turning left or turning right when sound was present or absent. We compared whether the female was more frequently walking or turning after sound was produced, as well as whether the female continued resting or searching 1-s after sound was produced, using $\chi^{2}$ analysis.

To determine if there appeared to be a kinesis, or increase in turning frequency, we examined the number of turns by females as they approached a host. Due to the angle of the video camera, we could not determine the absolute distance from the host to the searching female. Therefore, assuming that it takes longer to travel a longer distance than a shorter distance, the time between landing and oviposition was used as a proxy for distance from the host. Analysis of variance was used to compare the mean number of turns per minute when females took $0-4$ and 5-8 min before probing. Correlation and regression analyses were conducted to compare the number of larval feeding sounds per minute to the number of female turns per minute, for up to ten feeding sounds per minute. All analyses were conducted using SAS Institute (1996).

The choice experiment was analyzed using $\chi^{2}$ analysis to test the null hypothesis that there was no difference in landing frequency on the ends of logs containing active and paralyzed host larvae. To test the null hypothesis that there was no relationship between movement or direction of movement in response to sound (a taxis), the frequencies of movement towards a larva, away from a larva, or no movement following sound production were analyzed using a $G$-test (SAS Institute 1996).

\section{Results}

Searching behavior

Host finding behavior was initiated after a female S. lepidus landed on a $\log$ and began walking or turning, and terminated with drilling the ovipositor into the log. Data on the frequency and duration of behavioral events were recorded for 17 females
(Table 1). The principal behavioral loop consisted of walking, turning and resting (Fig. 1, Table 1). Walking or turning movements were short, usually lasting 1-2 s, whereas resting, probing and grooming behaviors had longer durations. A resting event typically lasted approximately $10 \mathrm{~s}$ while grooming bouts typically lasted about $30 \mathrm{~s}$. Positioning the abdomen for probing generally lasted $\sim 80 \mathrm{~s}$, and was characterized by the wasp raising the distal tip of the abdomen and curving the ovipositor under its body to drill through the wood. Probing (drilling) followed positioning, and consisted of the wasp twisting and drilling the ovipositor into the wood. Probing was long and arduous, typically lasting about $40 \mathrm{~min}(63.44 \%$ of the time budget) (Table 1$)$. The mean time from the start of host searching to initiation of probing was $18.78 \pm 5.54 \mathrm{~min}$. Larval feeding sounds were intermittent and characterized by clicks and snapping sounds of variable duration.

There was no significant difference in the mean resting times prior to turning left (tl), turning right (tr) or walking $(\mathrm{w})$ for all 17 females $(\mathrm{tl}=12.19 \pm 0.93$; $\operatorname{tr}=11.29 \pm 0.67 ; \quad w=10.05 \pm 0.70) \quad(F=1.67$, df $=2,906, P=0.190)$. On the seven tracks with sound, the resting duration before turning left, turning right or walking was not significantly different, whether sound was present or absent $(F=1.12$, df $=2,119, \quad P=0.33 \quad 1 ; \quad F=1.10, \quad$ df $=2,138$, $P=0.336$ ). However, insects were more likely to become active rather than remain resting $1 \mathrm{~s}$ after a larval feeding sound occurred (Fig. 2).

The mean number of turns per female per minute was higher $0-4 \mathrm{~min}$ before probing than 5-8 $\mathrm{min}$ before probing $(F=5.16$, $\mathrm{df}=1,100, P=0.025)$ (Fig. 3). The number of sounds produced by a feeding host larva per minute was moderately correlated to the number of turns by searching females per minute ( $r=0.377)$, and there was a positive relationship between the number of sounds produced and the number of turns by a female $S$. lepidus. A regression of these variables was significant $\left(r^{2}=0.142, N=\right.$ $37, F=5.97, P=0.02, y=2.46+0.26 x)$.

Choice experiment: active or immobilized larvae

In the choice test where parasitoid females $(N=25)$ were given active or immobilized inactive larvae in the same log, the searching frequency on the two groups should have been similar (50\% active: $50 \%$ 
Table 1 Frequency and duration of host searching behavioral events for female S. lepidus attacking Phoracantha recurva larva in Eucalyptus logs $(n=17)$

\begin{tabular}{lrlll}
\hline Behavioral event & $N$ & $\begin{array}{l}\text { Event duration }(\mathrm{s}) \\
\text { (Mean } \pm \text { SE) }\end{array}$ & Total time in event (s) & \% of total time \\
\hline Rest & 1016 & $11.86 \pm 0.50$ & 12,065 & 24.30 \\
Turn right & 352 & $1.61 \pm 0.06$ & 565 & 1.10 \\
Turn left & 335 & $1.75 \pm 0.07$ & 587 & 1.20 \\
Walk & 322 & $2.22 \pm 0.22$ & 716 & 1.50 \\
Position & 48 & $80.42 \pm 12.33$ & 3860 & 7.80 \\
Probe & 13 & $2423.62 \pm 545.68$ & 31,507 & 63.44 \\
Step right & 11 & $1.27 \pm 0.14$ & 14 & 0.02 \\
Step left & 6 & $1.83 \pm 0.17$ & 11 & 0.02 \\
Antennate & 10 & $1.60 \pm 0.16$ & 16 & 0.03 \\
Groom & 10 & $32.00 \pm 17.07$ & 320 & 0.64 \\
Total & 2123 & - & 49,663 & - \\
\hline
\end{tabular}

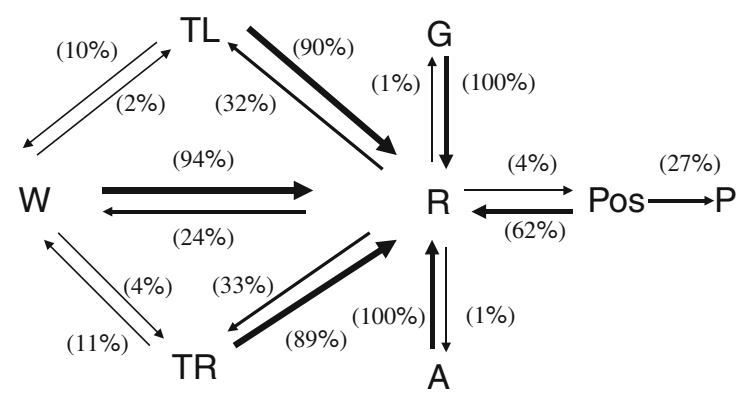

Fig. 1 Behavioral events of searching female S. lepidus include walking (W), turning left (TL), turning right (TR), resting $(\mathrm{R})$, grooming $(\mathrm{G})$, antennating $(\mathrm{A})$, positioning for probe (POS), and probing (P). A total of 2123 events were included from 17 females. Arrow thickness indicates relative frequency of events. Graphic can be interpreted as follows: Walking leads to resting $94 \%$, to TR $4 \%$, and to TL $2 \%$

inactive). However, the parasitoids conducted their searches significantly more often $\left(\chi^{2}=9.0, \mathrm{df}=1\right.$, $P<0.005)$ over active larvae $(N=20,80 \pm 8.0 \%$. mean $\% \pm \mathrm{SE})$ than immobile larvae $(N=5,20 \pm$ 8.0\%). Also, searching females moved towards or exhibited a taxis toward $(N=824)$ an active larva in response to host sounds significantly more often than moving away $(N=304)$ or exhibiting no movement $(N=156)(G=556.63, \mathrm{df}=2, P<0.001)$.

\section{Discussion}

Behavioral observations can provide insight into sensory mechanisms used to detect hosts. A wide

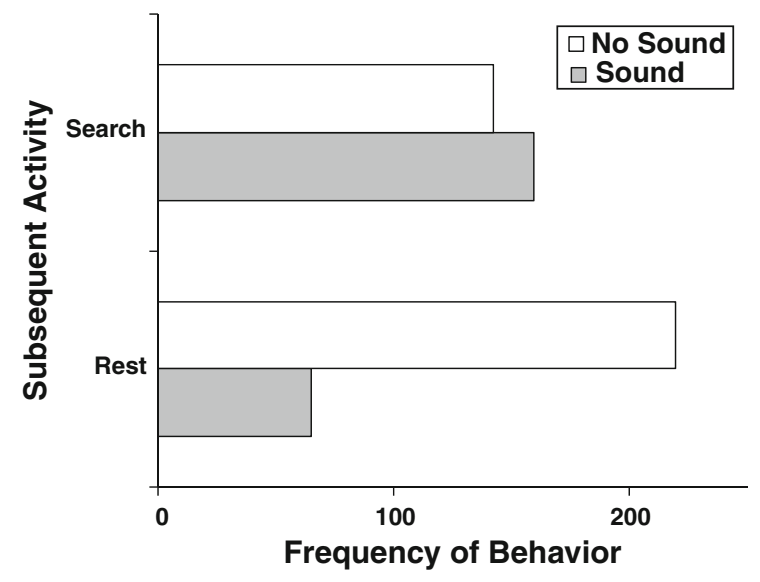

Fig. 2 The frequency of behaviors initiated by a resting female $S$. lepidus 1 -s after a larval feeding sound $\left(\chi^{2}=55.42\right.$, df $=1, P=0.001$ )

range of chemical cues (including plant volatiles, pheromones, secretions, scales, etc.) are associated with host finding by parasitoids (Godfray 1994; Quicke 1997). In addition, Salt (1935) first documented the use of external chemical markers that are deposited on parasitized hosts and deter subsequent oviposition. Frequent antennation of the substrate by a parasitoid could indicate searching for a chemical stimulus associated with hosts (Joyce et al. 1999). However, antennation was rarely exhibited by S. lepidus, suggesting that this species may not rely on chemical cues to locate hosts. In contrast, searching behavior of a female wasp was characterized by slow and deliberate walking while alternately 


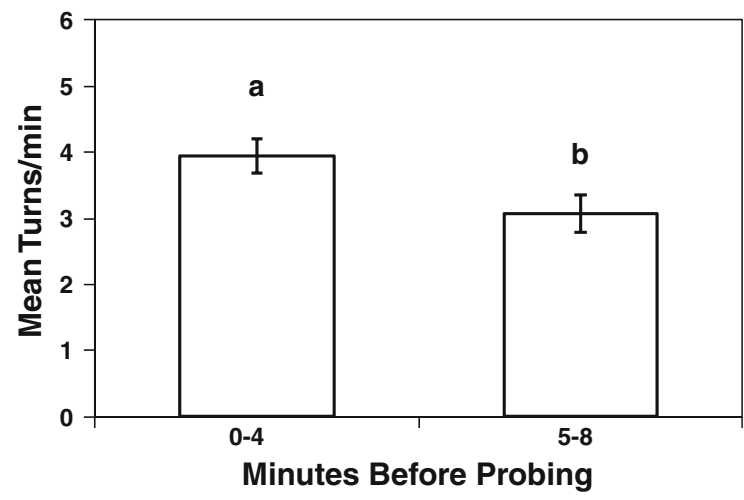

Fig. 3 Mean $( \pm$ SE) number of turns by searching females at 0-4 min prior to probing, compared to 5-8 min before probing $(F=5.16, P=0.025, \mathrm{df}=1,100)$

turning left and right as it approached a larva, and the wasp held its head upright and antennae forward. Several times a female stopped walking and momentarily touched her terminal antennal segments onto the log surface before she resumed walking.

The relatively slow walking, resting, and turning which characterize the searching behavior of S. lepidus females suggests that the wasp stops to rest and to wait for a host related cue, perhaps listening for sound or vibration associated with larval movement, and subsequently orients toward the source of the stimulus. Females on average took $18 \mathrm{~min}$ to walk, turn, and search a $\log$ section $<40 \mathrm{~cm}$ in length to localize a larval host, and another $40 \mathrm{~min}$ to drill through the log.

The responses of searching parasitoids in the choice experiment, to search more frequently near an active than immobilized host larva, also supports the hypothesis that chemical cues are not the primary stimuli exploited for host finding. Although it is possible that ovipositing females left a chemical mark over the paralyzed host which could deter subsequent females from probing that site, such a chemical mark could not be responsible for the lack of orientated movements towards a host from a distance. If the chemical marks were deposited, they would have been anywhere from one to five days old and would likely have degraded within the first $10 \mathrm{~h}$ (Chow and Mackauer 1986).

Other parasitoids, such as the pupal parasitoid Pimpla turionellae, detect hosts by perceiving echoes of self-produced vibrational signals that are sent with their antennae. This mechanism has been termed vibrational sounding, and may be widespread in Hymenoptera (Wackers et al. 1998; Broad and Quicke 2000). This form of host finding by echo location is characterized by frequent drumming of the substrate with the antennae. Unlike $P$. turionellae, however, S. lepidus was rarely observed to antennate the substrate. Thus, it appears unlikely that S. lepidus use vibrational sounding to detect their larval hosts.

Female S. lepidus may detect substrate-borne acoustic signals produced by feeding of their larval hosts by means of a subgenal organ in the tibia as is suspected with vibrational sounding (Vilhelmsen et al. 2001). They might also detect near-field airborne sound via the Johnston's organ in the antennae, but it is difficult to distinguish between the substrate vibration and near-field sounds in this experiment. Both types of structures are known to occur in the Hymenoptera (McIndoo 1922; Dreller and Kirchner 1993). The cerambycid larvae are feeding at the interface of the inner bark and the wood, and feeding galleries of the larger larvae are deeply etched into the outer layers of xylem. The rasping of the mandibles on the woody tissues creates sounds that are clearly audible to the human ear from at least $2 \mathrm{~m}$ away as well as substrate vibrations. Small Phoracantha larvae feeding in the softer cambium and inner bark do not produce audible feeding sounds (ALJ, Pers. Obs.), but these larvae are detected by ovipositing females (Joyce et al. 2002; Paine et al. 2004). Therefore, S. lepidus may rely on substrate vibrations to detect hosts. Other insects and arachnids are known to use vibrations to detect direction to the vibration source (Cocroft et al. 2000; Hill 2009). If the subgenal organs in the legs are used to detect vibration, it is possible that the wide stance adopted in the "listening pose" while resting on the bark be critically important for detection of the direction to the source of vibration, via the time delay in the vibrational signal hitting one set of legs versus the other. Analogous mechanisms for determining directionality in vibrational signaling have been proposed for pentatomid bugs (reviewed in Cokl and Virant-Doberlet 2003).

Wasps began walking, turning right, or turning left more frequently shortly after initiation of larval feeding ( $<1 \mathrm{~s})$ than 1-7 s after sound initiation, and movement was directed towards the source of the acoustic cues. Because host feeding sounds are produced intermittently, it is probably beneficial for 
searching wasp females to respond immediately after the stimulus is perceived. Wasps were more likely to search than rest $1 \mathrm{~s}$ after a host sound was produced, again suggesting that the sound stimulates searching activity. The number of turns per minute by searching females was moderately correlated with the number of sounds produced by each larva, and the increase in turning rate as the wasp homed in on her prey suggests that the wasp is responding to a stronger local stimulus when in close proximity to the host.

Female S. lepidus detect and orient toward the larval produced sounds/vibrations associated with their hosts. Further experiments might investigate whether parasitoid wasps use acoustic cues to assess quality or size of hosts. Consideration of the transmission of host produced vibrations in rearing substrates could improve the production of parasitoids when mass rearing for augmentative biological control.

Acknowledgments A. L. J. gratefully acknowledges financial support from the van den Bosch scholarship from University of California Berkeley. We thank Jim Brown and Gary Croll of Media Resources, University of California, Riverside for providing studio space and recording equipment. Julio Bernal provided helpful comments on the manuscript. Jose Arredondo and Luis Martinez assisted with rearing insect colonies and technical support.

Open Access This article is distributed under the terms of the Creative Commons Attribution Noncommercial License which permits any noncommercial use, distribution, and reproduction in any medium, provided the original author(s) and source are credited.

\section{References}

Austin AD, Quicke DLJ, Marsh PM (1994) The hymenopterous parasitoids of eucalypt longicorn beetles, Phoracantha spp (Coleoptera: Cerambycidae) in Australia. Bull Entomol Res 84:145-174

Broad GR, Quicke DLJ (2000) The adaptive significance of host location by vibrational sounding in parasitoid wasps. Proc R Soc Lond B 267:2403-2409

Chow FJ, Mackauer M (1986) Host discrimination and larval competition in the aphid parasite Ephedrus californicus. Entomol Exper et Appl 41:243-254

Cocroft RB, Tieu TD, Hoy RR, Miles RN (2000) Directionality in mechanical response to substrate vibration in a treehopper (Hemiptera: Membracidae: Umbonia crassicornis). J Comp Physiol A 186:695-705

Cokl A, Virant-Doberlet M (2003) Communication with substrate-borne signals in small plant-dwelling insects. Annu Rev Entomol 48:29-50
Djemai I, Casas J, Magal C (2004) Parasitoid foraging decisions mediated by artificial vibrations. Anim Behav 67:567-571

Dreller C, Kirchner WH (1993) Hearing in honeybees: localization of the auditory sense organ. J Comp Physiol A 173:275-279

Froggatt WW (1916) Forest longicorn beetles and their parasites. Agr Gaz New S Wales 16:561-567

Godfray HCJ (1994) Parasitoids: behavioral and evolutionary ecology. Princeton Press, Princeton, NJ, p 743

Hanks LM, McElfresh JS, Millar JG, Paine TD (1993) Phoracantha semipunctata F (Coleoptera: Cerambycidae), a serious pest of Eucalyptus in California: biology and laboratory rearing procedures. Ann Entomol Soc Am 86:96-102

Hanks LM, Campbell C, Paine TD, Millar JG (1997) Host range expansion of Helcostizus rufiscutum Cushman (Hymenoptera: Ichneumonidae) to Phoracantha semipunctata F. (Coleoptera: Cerambycidae) in California. Pan-Pac Entomol 73:190-191

Hanks LM, Millar JG, Paine TD, Wang Q (2001) Patterns of host utilization by two parasitoids (Hymenoptera: Braconidae) of the Eucalyptus longhorned borer (Coleoptera: Cerambycidae). Biol Control 21:152-159

Hill PSM (2009) How do animals use substrate-borne vibrations as an information source? Naturwiss 96:1355-1371

Joyce AL, Bellows TS Jr, Headrick D (1999) Reproductive biology and search behavior of Amitus bennetti (Hymenoptera: Platygasteridae), a parasitoid of Bemisia argentifolii (Homoptera: Aleyrodidae). Environ Entomol 28:282-289

Joyce AL, Millar JG, Paine TD (2002) The effect of host size on the sex ratio of Syngaster lepidus a parasitoid of eucalyptus longhorned borers (Phoracantha spp.). Biol Control 24:207-213

Joyce AL, Hunt RE, Bernal JS, Vinson SB (2008) Substrate influences mating success and transmission of courtship vibrations for the parasitoid Cotesia marginiventris. Entomol Exper et Appl 127:39-47

Joyce AL, Aluja M, Sivinski J, Vinson SB, Ramirez-Romero R, Bernal JS, Guillen L (2010) Effect of continuous rearing on courtship acoustics of five braconid parasitoids, candidates for augmentative biological control of Anastrepha species. BioControl. doi:10.1007/s10526-010-9278-x

McIndoo NE (1922) The auditory sense of the honeybee. J Comp Neurol 34:173-199

Meyhofer RJ, Casas J (1999) Vibratory stimuli in host location by parasitic wasps. J Insect Physiol 45:967-971

Meyhofer RJ, Casas J, Dorn S (1997) Vibration-mediated interactions in a host-parasitoid system. Proc R Soc Lond B 264:261-266

Millar JG, Paine TD, Campbell CD, Hanks LM (2002) Methods for rearing Syngaster lepidus and Jarra phoracantha (Hymenoptera: Braconidae), larval parasitoids of the phloem-colonizing longhorned beetles Phoracantha semipunctata and $P$ recurva (Coleoptera: Cerambycidae). Bull Entomol Res 92:141-146

Mills NJ, Kruger K, Schlup J (1991) Short-range host location mechanisms of bark beetle parasitoids. J Appl Entomol 111:33-43

Moore KM (1963) Observations on some Australian forest insects. 15. Some mortality factors of Phoracantha 
semipunctata (F.) (Coleoptera: Cerambycidae). Proc Linn Soc N S W 38:221-229

Paine TD, Millar JG (2002) Insect pests of eucalypts in California: implications of managing invasive species. Bull Entomol Res 92:147-151

Paine TD, Paine EO, Hanks LM, Millar JG (2000) Resource partitioning among parasitoids (Hymenoptera: Braconidae) of Phoracantha semipunctata in their native range. Biol Control 19:223-231

Paine TD, Dahlsten DL, Millar JG, Hoddle MS, Hanks LM (2001) UC scientists apply IPM techniques to new eucalyptus pests. Calif Agric 54:8-13

Paine TD, Joyce AL, Millar JG, Hanks LM (2004) The effect of variation in host size on the sex ratio, size, and survival of Syngaster lepidus, a parasitoid of Eucalyptus Longhorned Beetles (Phoracantha spp.). II. Biol Control 30:374-381

Quicke DLJ (1997) Parasitic wasps. Chapman \& Hall, London, UK

Richerson JV, Borden JH (1971) Sound and vibration are not obligatory host finding stimuli for the bark beetle parasite, Coeloides brunneri (Hymenoptera: Braconidae). Entomophaga 16:95-99

Salt G (1935) Experimental studies in insect parasitism III. Host selection. Proc R Soc Lond B 117:413-435
SAS Institute (1996) SAS user's guide for statistics. SAS Institute, Cary, NC

Scriven GT, Reeves EL, Luck RF (1986) Beetle from Australia threatens eucalyptus. Calif Agric 40:4-6

Sokolowski MB, Turlings TCJ (1987) Drosophila parasitoidhost interactions: vibrotaxis and ovipositor searching from the host's perspective. Can J Zool 65(46):1-464

Sugimoto T, Shiinono Y, Hata Y, Nakai A, Yahara M (1988) Foraging for patchily-distributed leaf-miners by the parasitoid, Dapsilarthra rufiventris (Hymenoptera: Braconidae) III. Visual and acoustic cues to a close range patch-location. Appl Entomol Zool 23:113-121

Vilhelmsen L, Isidoro N, Romani R, Basibuyuk HH, Quicke DLJ (2001) Host location and oviposition in a basal group of parasitic wasps: the subgenal organ, ovipositor apparatus and associated structures in the Orussidae (Hymenoptera, Insecta). Zoomorphol 121:63-84

Vinson SB (1976) Host selection by insect parasitoids. Annu Rev Entomol 21:109-133

Wackers FL, Mitter E, Dorn S (1998) Vibrational sounding by the pupal parasitoid Pimpla (Coccygomimus) turionellae: an additional solution to the reliability-detectability problem. Biol Control 11:141-161 